\title{
Submonthly Variability in the South American Monsoon System
}

\author{
Hsi-Yen MA and C. Roberto MECHOSO \\ Department of Atmospheric and Oceanic Sciences, University of California Los Angeles, Los Angeles, \\ California, USA
}

(Manuscript received 10 March 2006, in final form 29 August)

\begin{abstract}
In this study, we examine the South American Monsoon System (SAMS) variability with an emphasis on three-day periods or longer during which time the low-level wind in central Amazonia is consistently from the west or the east (westerly and easterly wind regimes, WWRs and EWRs, respectively). We use observational and Reanalysis datasets for the southern summer, as in previous studies on SAMS variability. Our research methodology involves the addition of model data that consists of the Coordinated Enhanced Observing Period (CEOP) Model Output Location Time Series (MOLTS) at locations in the SAMS region, and ensemble atmospheric general circulation model (AGCM) simulations of the southern summer season.

For both wind regimes, the observed and simulated composites of anomalous precipitation over South America show a dipole pattern with poles in northwestern and central-southeastern Brazil. During WWRs (EWRs), precipitation anomalies at the central-southeastern pole are positive (negative), indicating a stronger (weaker) SACZ. In addition, during WWRs the upper-level monsoon high is stronger and the subtropical jet in the South American sector is stronger and closer to the equator.

We also examine the diurnal cycle of rainfall from three CEOP MOLTS for Rondonia and Brasilia, which are situated at different poles of the rainfall anomalies dipole. The diurnal cycle in precipitation during both wind regimes shows an early-afternoon maximum at the selected locations. At Rondonia (Brasilia), there is a second early-morning (nocturnal) maximum on EWR (WWR) days. The diurnal mean precipitation in the regime that shows this maximum value, which is primarily due to enhanced cumulus convection, is higher than that in the other regime. In the simulation, WWRs and EWRs occur with approximately equal frequency. There is also a dipole pattern in anomalous precipitation during the days of each regime, although the poles are displaced relative to the observations. The simulated diurnal cycles of rainfall for the different wind regimes are nearly identical. Possible explanations for these AGCM difficulties are briefly discussed.

Lag composites of geopotential height anomalies at $700 \mathrm{mb}$ prior to the establishment of the wind regimes in Amazonia show the development of structures in the South Pacific that resemble the principal modes of variability in that region. This indicates the existence of links between the wind regimes and the modes of intraseasonal variability over South America. It is proposed that the wind regimes are associated with low-frequency variability in the extratropical circulation.
\end{abstract}

Corresponding author: Hsi-Yen Ma, Department of Atmospheric and Oceanic Sciences, University of California, Los Angeles, 7127 Math Sciences Building, 405 Hilgard Avenue, Los Angeles, California 90095-1565, USA. Email: hyma@atmos.ucla.edu

(C) 2007, Meteorological Society of Japan

\section{Introduction}

The South American Monsoon System (SAMS) develops during the southern spring when the region of intense convection in northwestern South America shifts rapidly to the southern Amazon Basin and Brazilian Highlands. The Bolivian high-Nordeste trough system is firmly established during mid-summer. 
The South American Convergence Zone (SACZ) is an outstanding component of SAMS, extending southeastward from the continent over the Atlantic Ocean. SAMS begins to decay in February and continues to weaken throughout the southern fall as convection gradually retreats toward the equator. Additional details of SAMS can be found in Nogues-Paegle et al. (2003) and Vera et al. (2006), as well as references therein.

The availability of high-quality data from the multi-platform Tropical Rain Measuring Mission (TRMM) satellite and several field programs, notably the Large-Scale Biosphere Atmosphere Experiment in Amazonia (LBA), has renewed general interest in the many scientific issues associated with SAMS. In particular, LBA's TRMM-Wet Season Atmosphere Mesoscale Campaign (WETAMC) and related activities have provided detailed information on the diurnal cycle and variability of convection and rainfall at a location in Amazonia (Rondonia site; $61.87^{\circ} \mathrm{W}, 9.83^{\circ} \mathrm{S}$; Fig. 1) during the development of SAMS in 1999.

We first consider the diurnal cycle in Rondonia. Machado et al. (2002) examined daily variations in the total, high, and convective cloud fractions estimated using data from the Geostationary Operational Environmental Satellite (GOES) 8, as well as rainfall estimated from ra-

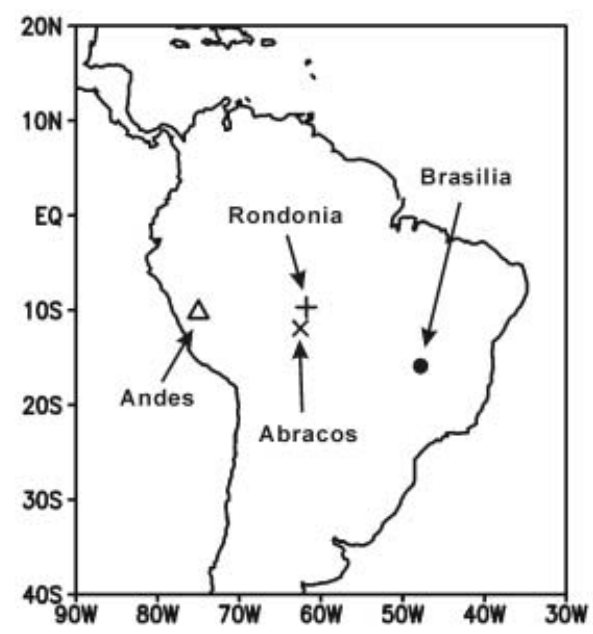

Fig. 1. Geographical locations referred to in this study: Rondonia $\left(+; 61.87^{\circ} \mathrm{W}\right.$, $\left.9.83^{\circ} \mathrm{S}\right)$, Brasilia $\left(\bullet ; 47.81^{\circ} \mathrm{W}, 16.01^{\circ} \mathrm{S}\right)$, Abracos site $\left(\times ; 62.5^{\circ} \mathrm{W}, 12^{\circ} \mathrm{S}\right)$, and 'An$\operatorname{des}^{\prime}\left(\Delta ; 75^{\circ} \mathrm{W}, 10^{\circ} \mathrm{S}\right)$. dar data and measured using raingauges. The minimum and maximum cloud cover occurs around 1200 and 0400, respectively (all times are Local Standard Times). Convection starts to develop when the total cloud fraction is at a minimum and solar radiation reaching the surface is at a maximum. High and convective cloud fractions increase rapidly to a maximum at about 1600 , while the maximum rainfall occurs at approximately 1400. Silva Dias et al. (2002) argued that the development of deep convection is delayed until the early afternoon because of the cooling effect on the PBL of shallow clouds and early-morning showers. The delay between the peak cloudiness and rainfall is longer if it is obtained from rain gauge and radar data rather than from precipitation estimates based on satellite data such as the GOES Precipitation Index or equivalent indirect measures such as Outgoing Longwave Radiation (OLR).

The diurnal cycle of rainfall described above is variable at submonthly time-scales. Based on soundings undertaken at the Abracos site (Fig. 1), Rickenbach et al. (2002) recognized that convection and rainfall at locations in Amazonia during SAMS can vary substantially when comparing days during which the prevailing direction of low-level flow is persistently from the east (easterly wind regime; EWR) and days during which the flow is from the west (westerly wind regime; WWR). An intense mode, consisting of vertically developed convection, is associated with EWR days, while a weaker monsoon-type mode is associated with WWR days. In both wind regimes, maximum precipitation occurs during the early afternoon, although the peak on EWR days is slightly later than that on WWR days. Halverson et al. (2002) used radar and local sounding-network data at the Abracos site to study the thermodynamics and kinematics of air mass properties during the two wind regimes. They found that on EWR days, rainfall is higher and convective precipitation makes a greater contribution to the daily total.

EWRs and WWRs can also be defined in terms of wind anomalies, i.e., deviations from the summer mean. Jones and Carvalho (2002) and Carvalho et al. (2002) examined the National Centers for Environmental Prediction/ National Center for Atmospheric Research 
(NCEP/NCAR) Reanalysis dataset (Kalnay et al. 1996) and found that EWRs and WWRs, in terms of wind anomalies, have similar median durations of 5 and 4 days, respectively. The authors demonstrated that anomalous circulation, precipitation, and OLR (Liebmann and Smith 1996) patterns during the wind regimes are of continental scale; the authors referred to the corresponding periods as the 'active' and 'break' phases in SAMS. The anomalous OLR and precipitation patterns during both the active and break phases show a dipole over northwestern and central-southeastern Brazil. Jones and Carvalho (2002) suggested a link between SAMS breaks and episodes of Madden-Julian oscillation (MJO; Madden and Julian 1972). Gan et al. (2004) used both daily and pentad data from the NCEP/NCAR Reanalysis and OLR data to examine wet and dry periods in west-central Brazil during January. They found that wet and dry periods are associated with low-level westerly and easterly wind anomalies in the region, respectively. Namely, the approaches adopted by Jones and Carvalho (2002), Carvalho et al. (2002), and Gan et al. (2004) in understanding submonthly wind and rainfall anomalies during SAMS involved different starting points but led to consistent conclusions. This indicates that the periods of the wind regimes are largely independent of the location used for their definition.

To the best of our knowledge, one question that remains unanswered is whether the SAMS breaks (and associated wind regimes in Amazonia) are linked to the modes of intraseasonal variability over South America. Previous studies support the existence of such an association. For example, Robertson and Mechoso (2000) showed that at intraseasonal, interannual, and even interdecadal time scales, the dominant mode of variability over subtropical South America during the warm season consists of an anomalous, large-scale, and equivalent barotropic eddy. The cyclonic phase of the eddy is accompanied by weakened low-level flow east of the Andes and an intensified SACZ, while the anticyclonic phase is accompanied by the opposite conditions. Liebmann et al. (1999) found that intensified SACZ episodes at submonthly time scales are accompanied by a trough to the southwest that is produced by a transient Rossby wavetrain from higher latitudes. Diaz and Aceituno (2003) obtained a similar structure for the dominant mode of variability over South America during the warm season. The authors also suggested a relationship between intraseasonal variations over subtropical South America and upstream features in the South Pacific. The composites of geopotential height anomalies during EWR and WWR presented by Jones and Carvalho (2002) also show significant anomalies in the southeastern Pacific; the anomalies have a pattern that resembles a wavetrain.

The principal goal of the present paper is to gain a better understanding of the variability of SAMS at submonthly time scales. Our approach is based on an analysis of the variability of different wind regimes in central Amazonia. We start by using observational and Reanalysis datasets for the southern summer, as in previous studies. Our research methodology also involves the used of model data that consists of the Coordinated Enhanced Observing Period (CEOP) Model Output Location Time Series (MOLTS) at locations in the SAMS region and ensemble atmospheric general circulation model (AGCM) simulations of the southern summer season.

The remainder of the text is organized into five sections. Section 2 introduces the datasets, model, and methodology used in this study. Section 3 describes differences in rainfall and circulation during the two wind regimes, and Section 4 focuses on the diurnal cycle of precipitation in Rondonia and another location near the SACZ region. Section 5 discusses the links between the wind regimes and intraseasonal variability during the southern warm season. Finally, Section 6 presents a summary and discussion of the results.

\section{Datasets, model, and methodology}

\subsection{Datasets}

For the dynamical fields we use the NCEP/ NCAR Reanalysis dataset (Kalnay et al. 1996) corresponding to the December-JanuaryFebruary (DJF) austral summers over the period 1980-2004. For rainfall, we use the daily precipitation grids for South America compiled by Liebmann and Allured (2005). This dataset is based on information provided by approximately 7900 South American meteorological stations and is synthesized into daily fields on 
a $1^{\circ} \times 1^{\circ}$ grid. All the data fields are linearly interpolated to the horizontal grid used in the AGCM (see Section 2.2) with daily temporal resolution.

We also use the MOLTS provided to the CEOP by the NCEP, the Japan Meteorological Agency (JMA), and the United Kingdom Meteorology Office (UKMO). The MOLTS are vertical profiles of model output at locations chosen to approximately correspond to the Global Energy and Water Cycle Experiment (GEWEX) Reference Sites. Upon request from CEOP, the NCEP global data assimilation and forecast model provides three-hourly gridded data starting on December 1, 2002. The JMA global data assimilation system provides hourly intermediate gridded data starting on October 1, 2002. The UKMO provides data from the current operational version of the Global Unified Model at three-hourly intervals starting on October 1, 2002. A more detailed description of the models and data formats is available online at http:// www.eol.ucar.edu/projects/ceop/dm/model/. We utilize the MOLTS corresponding to DJF 2002-03 at two locations affected by SAMS (Fig. 1): Rondonia $\left(61.87^{\circ} \mathrm{W}, 9.83^{\circ} \mathrm{S}\right)$ and Brasilia $\left(47.81^{\circ} \mathrm{W}, 16.01^{\circ} \mathrm{S}\right)$.

\subsection{AGCM}

The University of California Los Angeles (UCLA) AGCM includes advanced parameterizations of the major physical processes in the atmosphere. The parameterization of cumulus convection, including its interaction with the PBL, follows the prognostic version of Arakawa and Schubert (1974) presented by Pan and Randall (1998). The parameterization of radiative processes is based on Harshvardhan et al. (1987, 1989), and the parameterization of PBL processes is based on the mixed-layer approach of Suarez et al. (1983), as revised by $\mathrm{Li}$ et al. $(1999,2002)$. A more detailed description of the model can be found in Arakawa (2000) and Mechoso et al. (2000), or online at http://www .atmos.ucla.edu/ mechoso/esm/agcm.html.

In the present study, we use model version 7.1 with a horizontal resolution of $2.5^{\circ}$ latitude and $2^{\circ}$ longitude, with 29 layers in the vertical (top at $1 \mathrm{mb}$ ). The prescribed sea-surface temperature fields correspond to the monthly climatology presented by Reynolds and Smith (1994). To produce several realizations of the si- mulated austral summer we perform six DJF ensemble simulations from slightly different initial conditions in early spring. The output is stored every hour; this enables the production of AGCM's MOLTS at the grid points closest to Rondonia and Brasilia $\left(62.5^{\circ} \mathrm{W}, 10^{\circ} \mathrm{S}\right.$ and $47.5^{\circ} \mathrm{W}, 16^{\circ} \mathrm{S}$, respectively).

\subsection{Methodology}

We apply the method of Rickenbach et al. (2002) to identify persistent wind regimes in both the Reanalysis and simulation. Accordingly, we examine the zonal component of the daily mean wind from the surface to $800 \mathrm{mb}$ at $62.5^{\circ} \mathrm{W}, 12^{\circ} \mathrm{S}$, which is the grid point closest to the Abracos site. If the signs of these wind components are continuously positive (negative) for at least three consecutive days, we define the corresponding period as a WWR (EWR) period. We also refer to the mean wind regime (MWR), which is the average for all of the days in the dataset.

Table 1 shows the total number of days assigned to the two wind regimes from the NCEP/NCAR Reanalysis according to the criterion proposed by Rickenbach et al. (2002). The number of WWR days shows significant interannual variability, and very few DJFs contain a substantial number of EWR days (1981,

Table 1. Number of days assigned to the two wind regimes from the NCEP/ NCAR Reanalysis. The year listed corresponds to the last month of the DJF period.

\begin{tabular}{lcc|ccc}
\hline Year & $\begin{array}{c}\text { Days of } \\
\text { westerly }\end{array}$ & $\begin{array}{c}\text { Days of } \\
\text { easterly }\end{array}$ & Year & $\begin{array}{c}\text { Days of } \\
\text { westerly }\end{array}$ & $\begin{array}{c}\text { Days of } \\
\text { easterly }\end{array}$ \\
\hline $1981^{*}$ & 50 & 20 & 1993 & 53 & 0 \\
1982 & 46 & 0 & 1994 & 76 & 0 \\
1983 & 60 & 0 & 1995 & 65 & 0 \\
1984 & 41 & 0 & 1996 & 67 & 4 \\
1985 & 44 & 6 & 1997 & 57 & 0 \\
$1986^{*}$ & 31 & 11 & 1998 & 39 & 0 \\
$1987^{*}$ & 12 & 11 & $1999^{*}$ & 22 & 9 \\
1988 & 66 & 0 & 2000 & 65 & 0 \\
1989 & 70 & 0 & 2001 & 49 & 0 \\
1990 & 60 & 0 & 2002 & 31 & 5 \\
1991 & 49 & 0 & $2003^{*}$ & 21 & 8 \\
1992 & 53 & 0 & 2004 & 59 & 0
\end{tabular}

* Year chosen for composite. Total westerly days for composite are 136 and total easterly days for composite are 59 . 
Table 2. Number of days assigned to the two wind regimes in the UCLA AGCM simulation.

\begin{tabular}{lcc}
\hline Exp & Days of westerly & Days of easterly \\
\hline 1 & 52 & 17 \\
2 & 44 & 10 \\
3 & 31 & 19 \\
4 & 45 & 24 \\
5 & 42 & 30 \\
6 & 43 & 21 \\
\hline total & 257 & 121 \\
\hline
\end{tabular}

1985, 1986, 1987, 1996, 1999, and 2003). In some years (e.g., 1985 and 1996), the duration of WWRs is much longer than that of EWRs. Therefore, the approximate balance between EWR and WWR days reported by Rickenbach et al. (2002) may be a peculiarity of the TRMMLBA year. For our comparison of the flows of the two wind regimes, we exclude 1985 and 1996 and retain 1996, 1981, 1986, 1987, 1999, and 2003.
Table 2 provides equivalent data as those in Table 1, except for the simulation. In this case, WWRs are similar in frequency to EWRs. This result may reflect an excessively weak mean flow in the simulation, as the AGCM result is similar to that obtained by Jones and Carvalho (2002) and Carvalho et al. (2002) with Reanalysis data, although these previous studies used wind anomalies in the regime definition.

\section{Rainfall and circulation during the wind regimes}

\subsection{Observations/Reanalysis}

Figure 2 shows composites of precipitation from observational data during the two wind regimes and $850 \mathrm{mb}$ wind anomalies from the NCEP/NCAR Reanalysis dataset. The shaded areas and vectors in this and other figures of the same type indicate values that are statistically significant at the $95 \%$ confidence level. The precipitation and wind anomalies in Fig. 2 are defined relative to the mean overall DJFs. Over South America, precipitation anomalies during both wind regimes form a dipole pat-

\section{$850 \mathrm{mb}$ Velocity and Precipitation Anomaly}
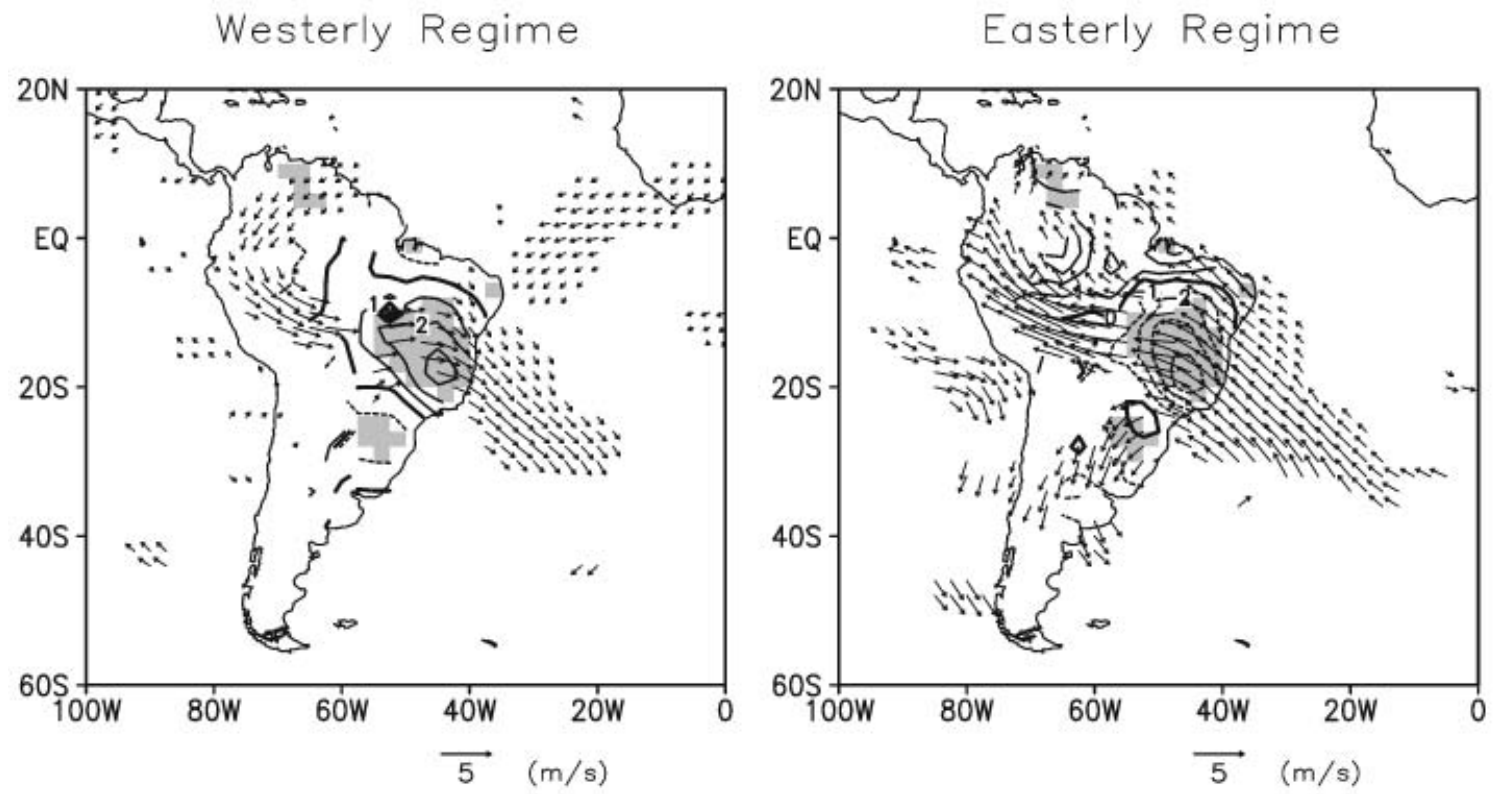

Fig. 2. Composites of observed precipitation (contours) and 850 (mb) velocity (arrows) anomalies during the westerly and easterly wind regimes, as derived from the daily precipitation grids for South America and the NCEP/NCAR Reanalysis, respectively. The contour interval for precipitation is 1.0 (mm day $\left.{ }^{-1}\right)$. The plotted anomalies are significant at the $95 \%$ confidence level. 


\section{$850 \mathrm{mb}$ Streamline and Windspeed (NCEP Reanalysis)}

Westerly Regime

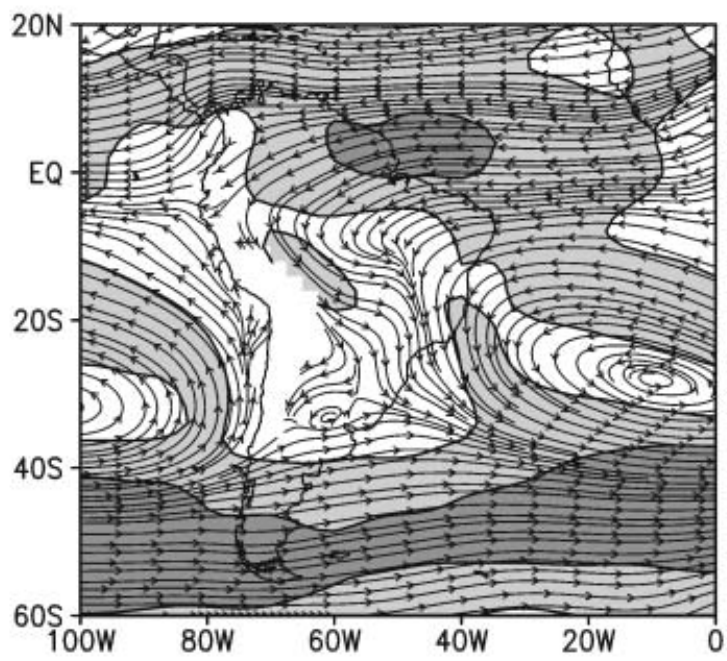

Easterly Regime

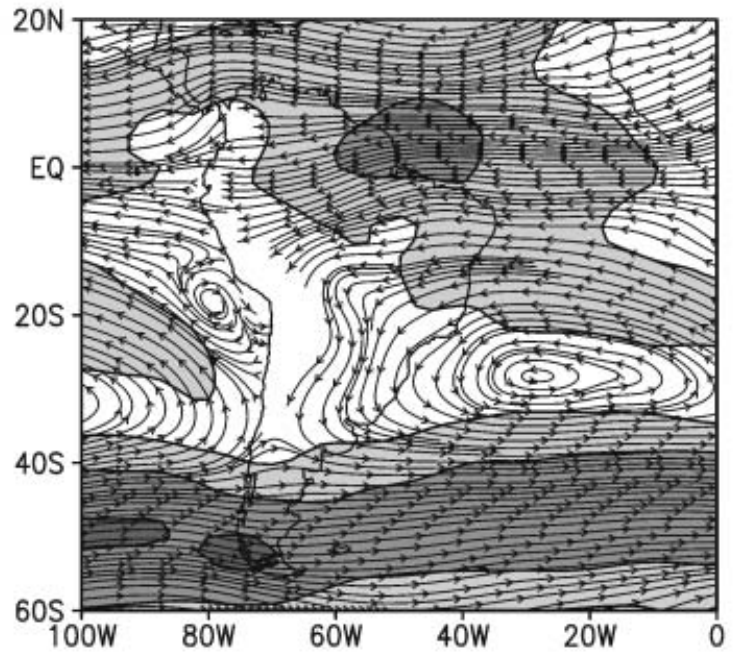

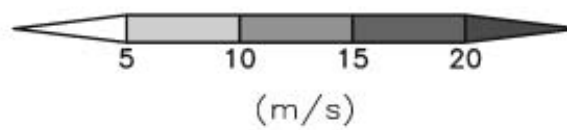

$200 \mathrm{mb}$ Streamline and Windspeed (NCEP Reanalysis)

Westerly Regime

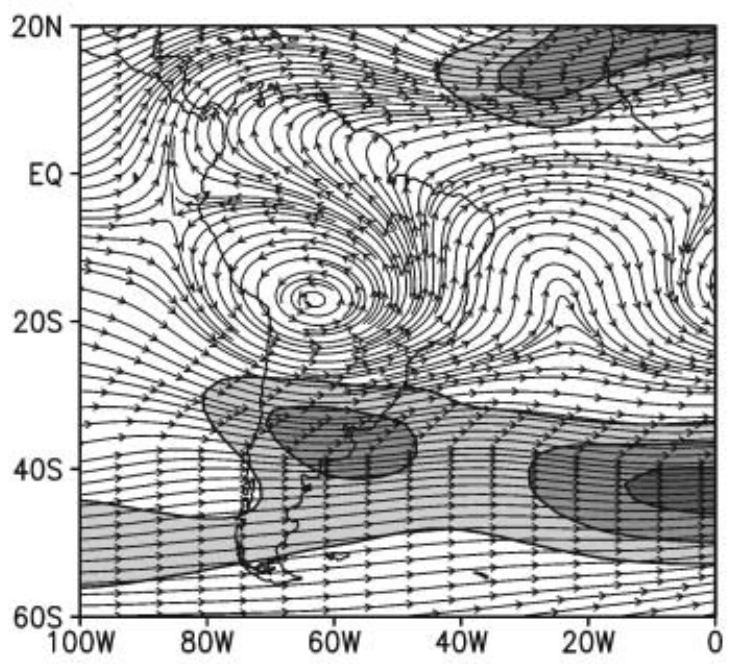

Easterly Regime

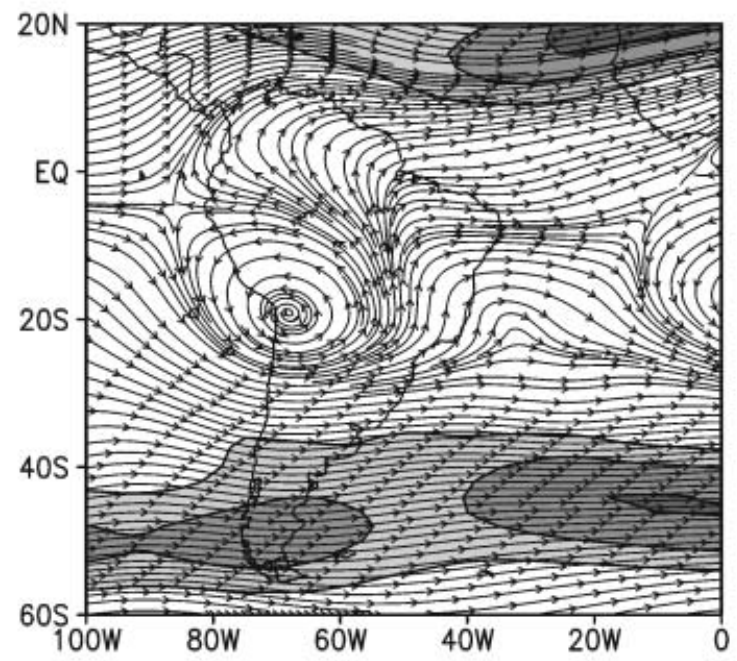

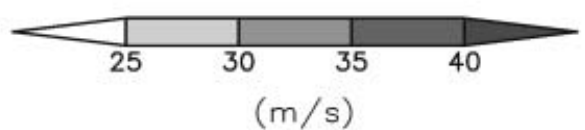

Fig. 3. Composites of 850 (mb) (top) and 200 (mb) (bottom) streamlines and wind speed (shaded) anomalies during the westerly and easterly wind regimes derived from the NCEP/NCAR Reanalysis. Contour interval is $5\left(\mathrm{~m} \mathrm{~s}^{-1}\right)$. 


\section{$850 \mathrm{mb}$ Velocity and Precipitation Anomaly}
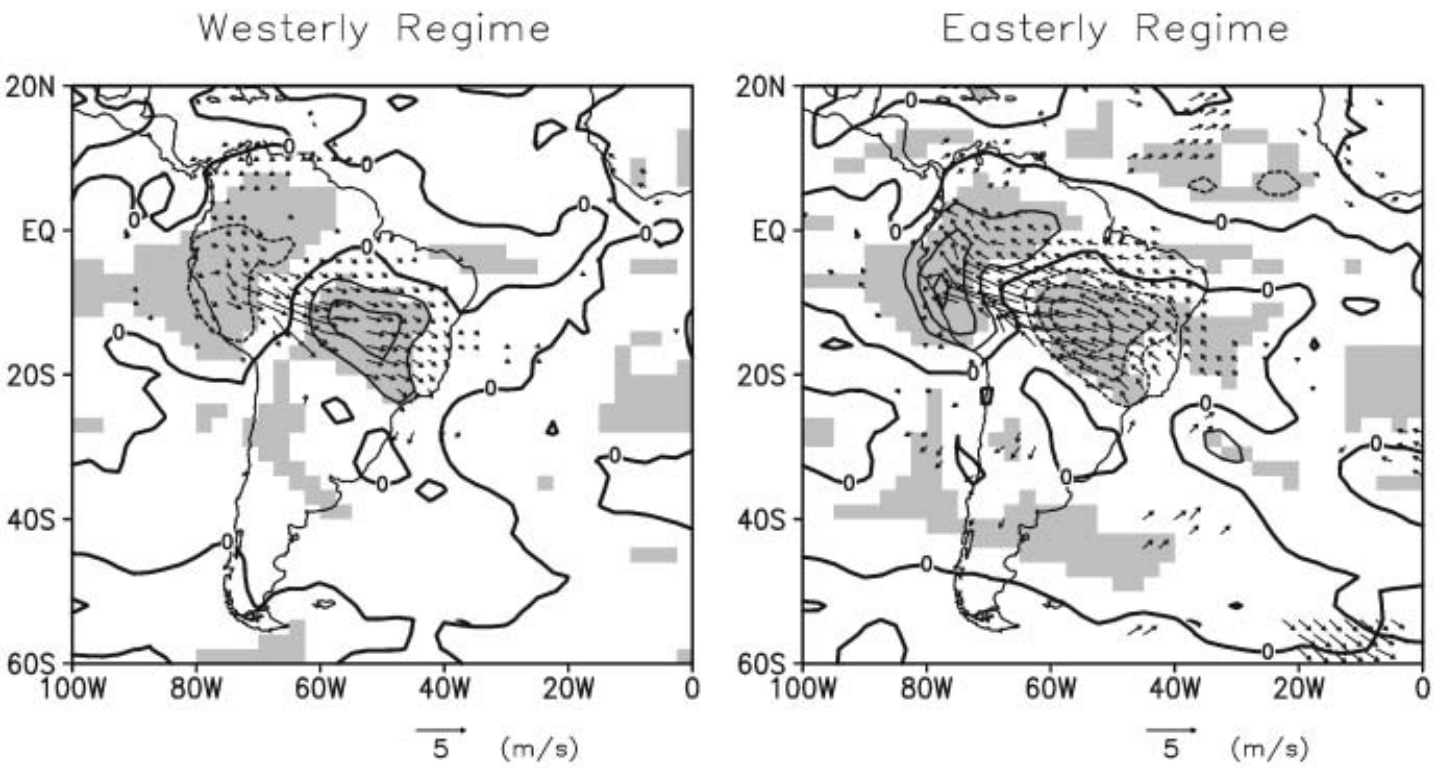

Fig. 4. Same as Fig. 2, except for simulation data.

tern, as reported by Jones and Carvalho (2002), Carvalho et al. (2002), and Gan et al. (2004). The northwestern pole of the dipole, located over northwest Brazil and the Andes, is not statistically significant; this may reflect insufficient data coverage in the region.

During WWR periods, the positive and negative centers of the dipole are located over central-southeastern and northwestern Brazil, respectively. The anomalous velocity field shows significant northwesterlies that are divergent at the negative pole and convergent at the positive pole. During EWR periods, the dipole configuration and anomalous velocity field is approximately opposite to that during WWR periods.

To further examine the continental-scale vertical structure of the circulation anomalies during the two wind regimes, we plotted composites of streamlines of the velocity field at 850 and $200 \mathrm{mb}$ (Fig. 3). At $850 \mathrm{mb}$ during WWR periods, the southern branch of the Atlantic subtropical high is located along the east coast of South America. The equatorial trade winds that flow from the Atlantic Ocean onto South America turn to northwesterlies around $70^{\circ} \mathrm{W}$, strengthen along the eastern side of the Andes, and extend into central South America. During EWR periods, the Atlantic subtropical high ex- tends further to the west over South America and the trades from the Atlantic become increasingly zonally oriented. At $200 \mathrm{mb}$, the monsoon high is stronger during WWR periods than EWR periods, and the subtropical jet stream in the South American sector is stronger and at lower latitudes during WWR periods. In this context, Jones and Carvalho (2002) related the wind regimes to active and break phases of the SAMS.

\subsection{Simulation}

Figure 4 presents composites of the simulated precipitation and $850 \mathrm{mb}$ velocity anomalies during the two wind regimes. The simulated dipole pattern in precipitation anomalies during both regimes is weaker and is displaced northwestward relative to observational data. During the WWR, the positive center of the dipole is located in central-southeastern Brazil and the negative center is located closer to the Andes. The anomalous velocity field shows significant northwesterlies that are divergent at the negative pole of the dipole and convergent at the positive pole. During the EWR, anomalies of both precipitation and wind are stronger and the dipole configuration is approximately the opposite of that during the WWR. At upper levels (Fig. 5), the simulated circulation over 


\section{$200 \mathrm{mb}$ Streamline and Windspeed (UCLA AGCM v7.1H)}

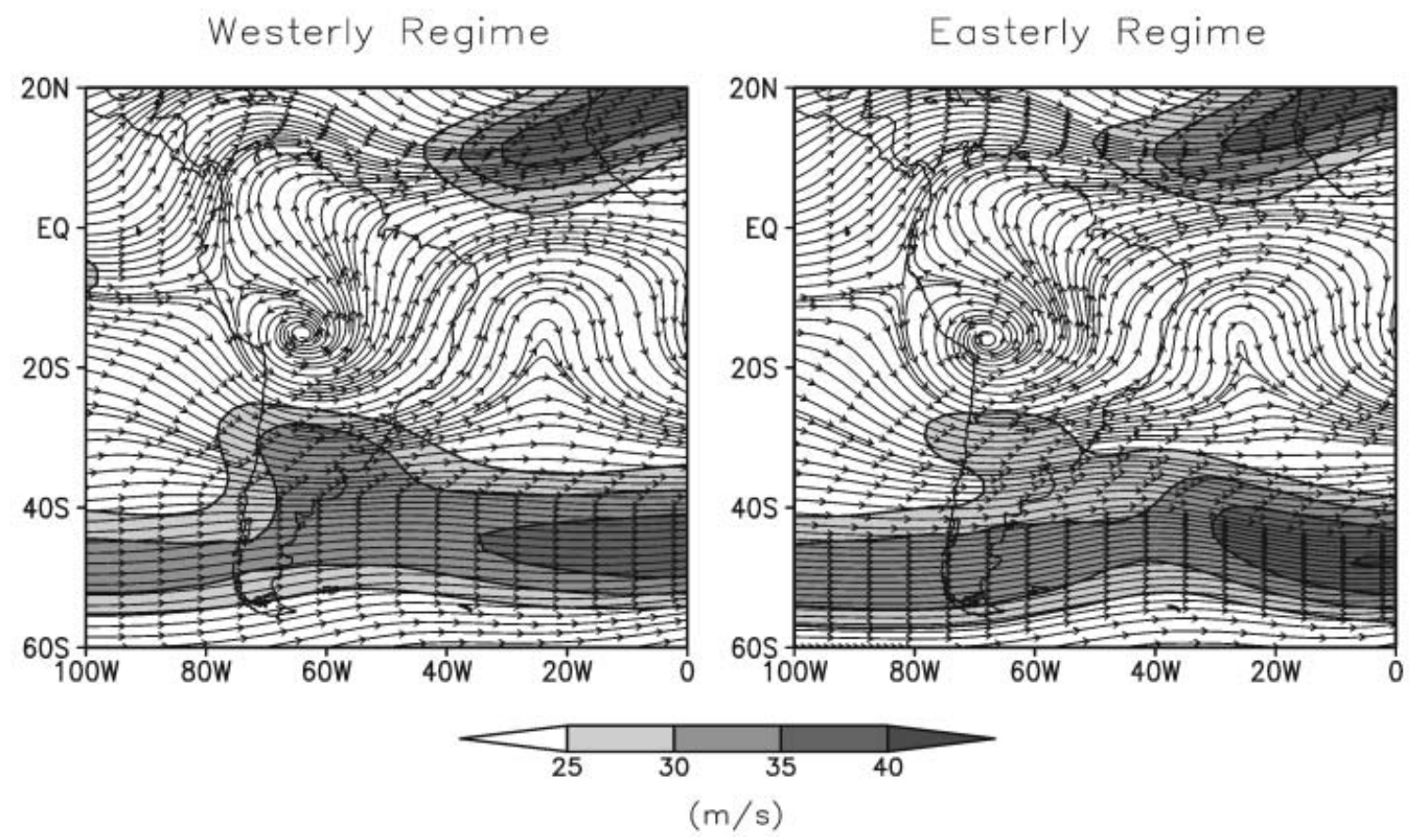

Fig. 5. Composites of $200(\mathrm{mb})$ streamlines and wind speed (shaded) anomalies during the westerly and easterly wind regimes, as derived from the simulation results. Contour interval is $5\left(\mathrm{~m} \mathrm{~s}^{-1}\right)$.

Amazonia during the two wind regimes has a higher degree of similarity than the observed circulation during the two wind regimes. This relative insensitivity is consistent with the weaker gradient in rainfall anomalies over Amazonia, which is dominated by just one of the poles.

Figure 6 shows the simulated vertical integrated moisture-flux anomalies during the two wind regimes. During the WWR (EWR), the anomalous moisture flux has a maximum over the Amazon Basin, which suggests the increased transport of moisture from the Andes region (central-southeastern Brazil) to centralsoutheastern Brazil (Andes region). This finding is consistent with the precipitation dipole pattern. The large values along the Atlantic coast are not associated with a significant rainfall anomaly (Fig. 4).

\section{Diurnal cycle during the wind regimes}

\subsection{Diurnal cycle of rainfall in the CEOP MOLTS}

In this sub-section, we use the CEOP MOLTS to investigate the diurnal cycle of rain- fall during the different wind regimes. MOLTS are available for Rondonia and Brasilia (Fig. 1), the two locations at the opposite poles of the dipole in rainfall anomalies that develops during the two wind regimes. We use the MOLTS provided by NCEP, JMA, and UKMO for DJF of 2002-03, during which time there was a substantial number of both westerly and easterly regimes (21 and 8, respectively, Table 1 ). The same composites of precipitation over Amazonia for the 2002-03 DJF season (not show) are similar to those shown in Fig. 2.

In numerical models of the type that produce the MOLTS compiled by CEOP, precipitation receives contributions from two different parameterizations, which represent the effects of large-scale condensation and convective processes in the atmosphere. Figures 7 and 8 show composites of the diurnal cycle in total (i.e., convective plus cumulus) and cumulus precipitation rate at Rondonia and Brasilia, as derived from MOLTS during the different wind regimes for DJF of 2002-03. To ensure consistency between different MOLTS data of composites for the periods of wind regimes, we use the 


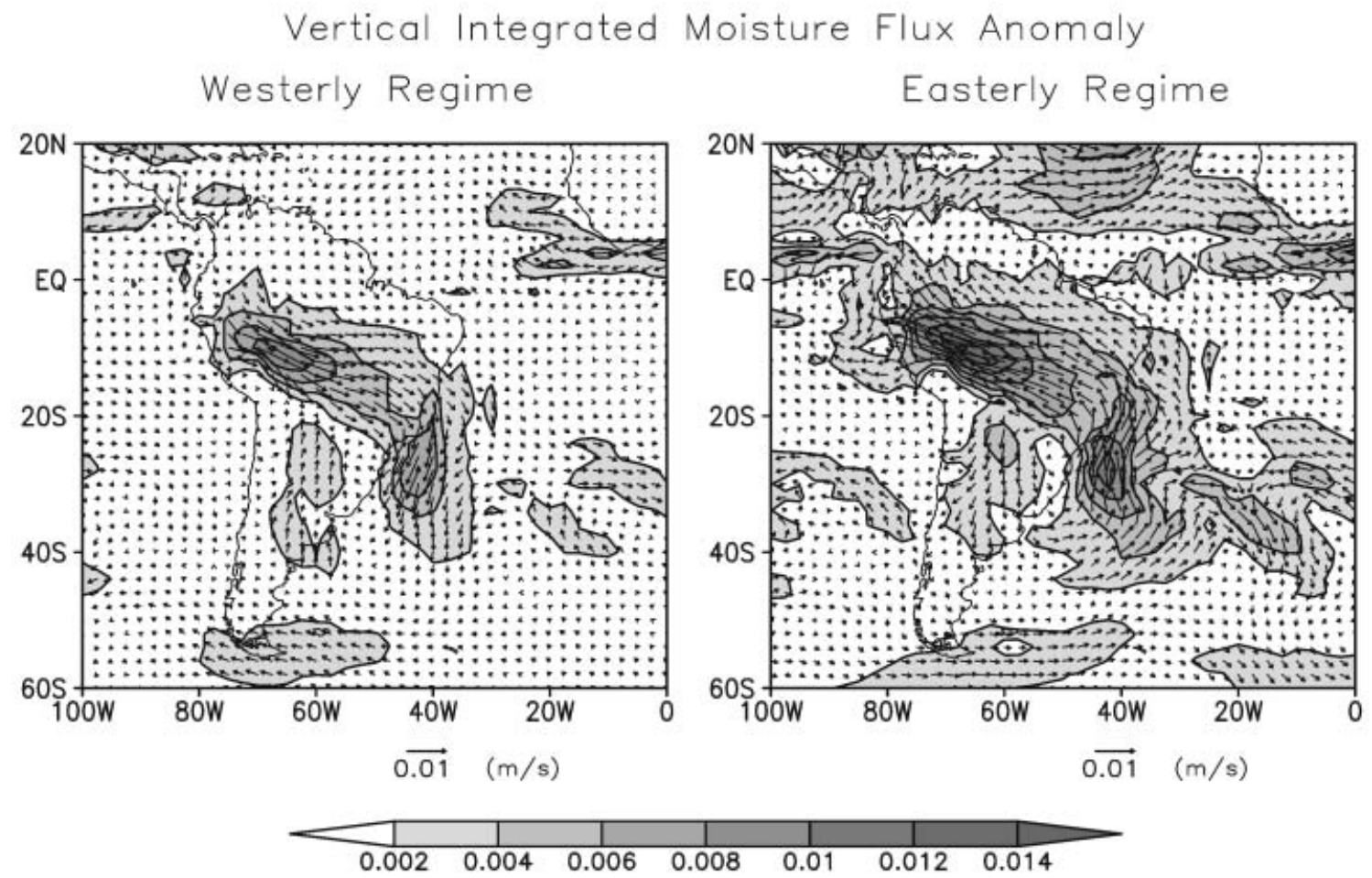

Fig. 6. Composites of the vertical integrated moisture-flux anomalies and magnitudes (shaded) during the westerly and easterly wind regimes, as derived from the simulation. Contour interval is $0.002\left(\mathrm{~m} \mathrm{~s}^{-1}\right)$.

NCEP/NCAR Reanalysis zonal velocity to determine EWR and WWR days, as in Rickenbach (2002).

At Rondonia (Fig. 7), total rainfall shows a peak in the afternoon and minimum values around noon and in the early morning. EWR days show another prominent maximum for all three MOLTS, although there are differences in terms of magnitude and timing. Previous studies (Betts et al. 2002; Cifelli et al. 2002; Marengo et al. 2002; Rickenbach et al. 2002; Rickenbach 2004 and references therein) have reported that the morning maximum during EWR days over Rondonia is due to the activity of mesoscale convective complexes and squall lines. WWR days have much weaker rainfall in the morning than in the afternoon. The early rainfall maximum on EWR days results in larger values of daily precipitation than those for WWR days, as mentioned in Section 3. As the separation of precipitation into large-scale and cumulus contributions is somewhat ambiguous and can be dependent on model resolu- tion, it may be unwise to attribute an unequivocal physical meaning to such a partition. Nevertheless, Fig. 7 strongly suggests that convective processes during EWRs provide the dominant contribution to both the afternoon peaks in rainfall and the stronger earlymorning rainfall.

The composites for Brasilia of the diurnal cycle in precipitation provided by MOLTS (Fig. 8) from different centers show stronger differences in the timings and magnitudes of rainfall peaks than those recorded between EWRs and WWRs at Rondonia. This finding may reflect the relatively small sample size at a location with strong interannual variability. In all three MOLTS sets considered in this study, total rainfall is lowest in the late morning and highest in the afternoon. EWRs do not show a second maximum in the early morning, and convective processes provide the dominant contribution to the afternoon peaks. Curiously, the NCEP MOLTS (Fig. 8A) show a peak after midnight that is even stronger than that in the 

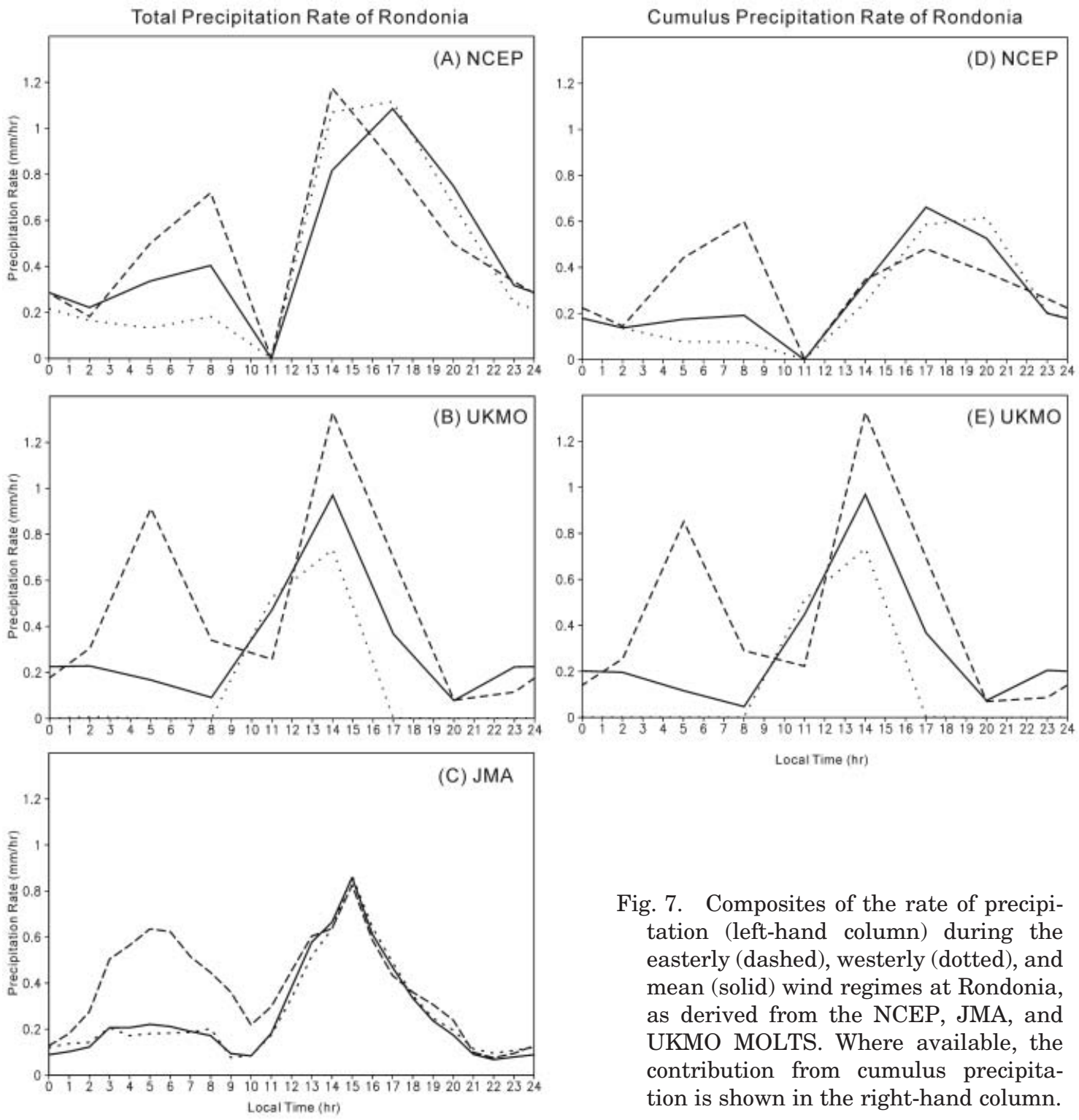

Fig. 7. Composites of the rate of precipitation (left-hand column) during the easterly (dashed), westerly (dotted), and mean (solid) wind regimes at Rondonia, as derived from the NCEP, JMA, and UKMO MOLTS. Where available, the contribution from cumulus precipitation is shown in the right-hand column.

afternoon. Daily precipitation is higher in the WWRs than in the EWRs, which is in agreement with the intraseasonal composites of precipitation at Brasilia (Fig. 2). According to the results shown in Fig. 8, both convective and large-scale precipitation are very active after midnight during the WWRs. The UKMO MOLTS (Fig. 7e), however, show that the total and cumulus precipitation are almost identical. The reasons for the different behaviors observed between different MOLTS require further investigation and verification using insitu data.

\subsection{Diurnal cycle of simulated rainfall}

In this sub-section, we examine the AGCM simulations of the diurnal cycle of rainfall at those grid points closest to the geographical locations of Rondonia and Brasilia. We then compare the simulations with the MOLTS composites used in Sub-section 4.1 (Figs. 7 and 8), although caution should be exercised in this regard because the latter correspond to a single southern summer (2002-03).

Figure 9 shows the simulated diurnal cycles of the total precipitation rate at Rondonia and Brasilia. As these two locations are in the same 

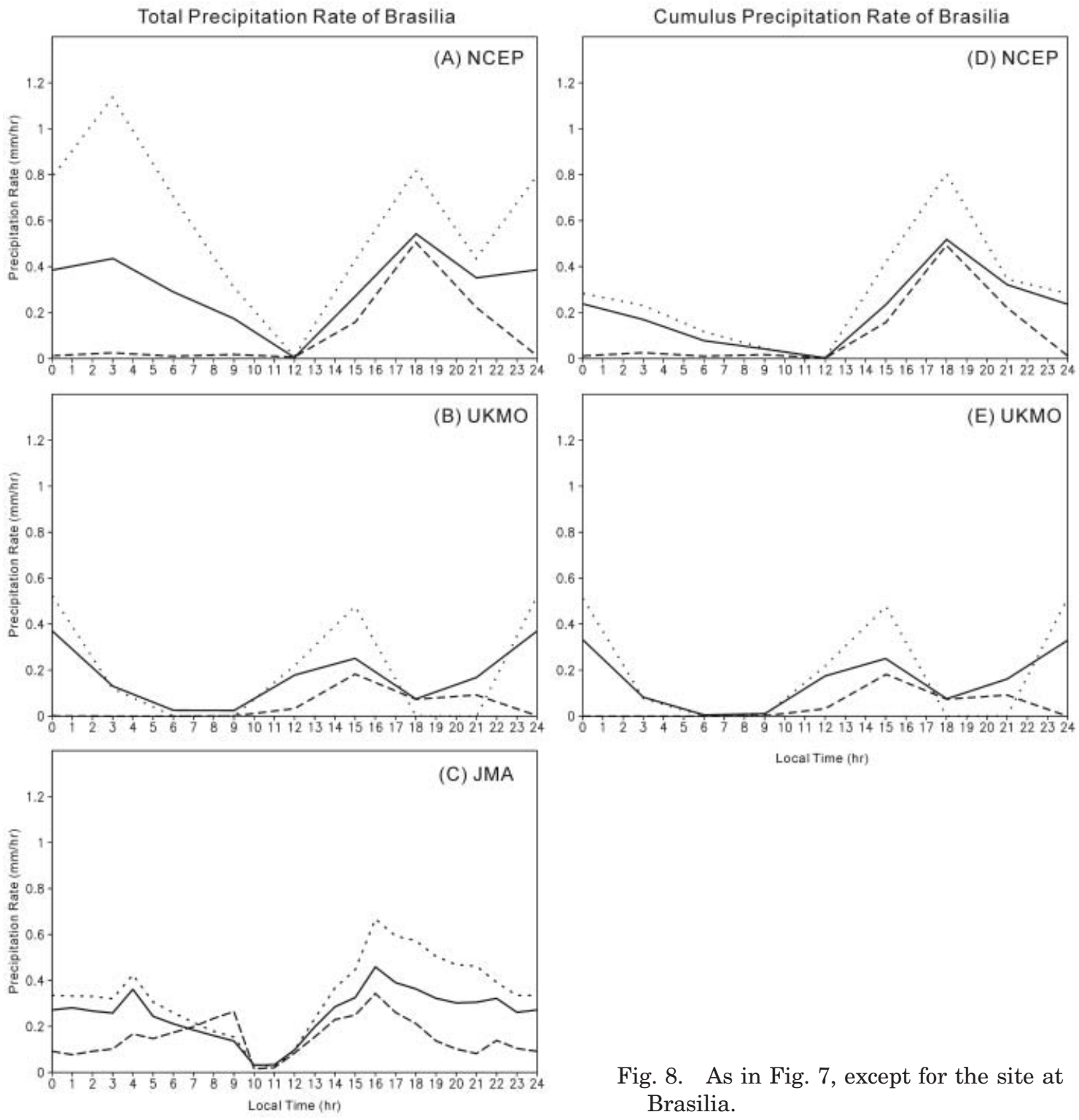

Local Time (hr)

pole of simulated rainfall anomalies, we add the location labeled 'Andes' in Fig. 1. In general, the simulated diurnal cycles of rainfall during WWRs and EWRs are largely identical at all locations, except for a small difference in amplitude. The simulated precipitation increases dramatically from around 1000 to reach maximum values around 1200 . These large values persist until approximately 1500 and decrease rapidly thereafter. The contribution from cumulus convection provides the early-afternoon peak, while the contribution of large-scale con- densation is approximately constant throughout the day (not shown).

The analysis of CEOP MOLTS revealed that the daily rainfall rate at Rondonia is higher during EWR periods than WWR periods; the opposite pattern is recorded at Brasilia. The simulation fails to reproduce this reversal because the two locations are situated within the same pole of the westerly-displaced dipole; however, the reversal is captured at the 'Andes' location situated over the Andes region at the other pole of the dipole. 

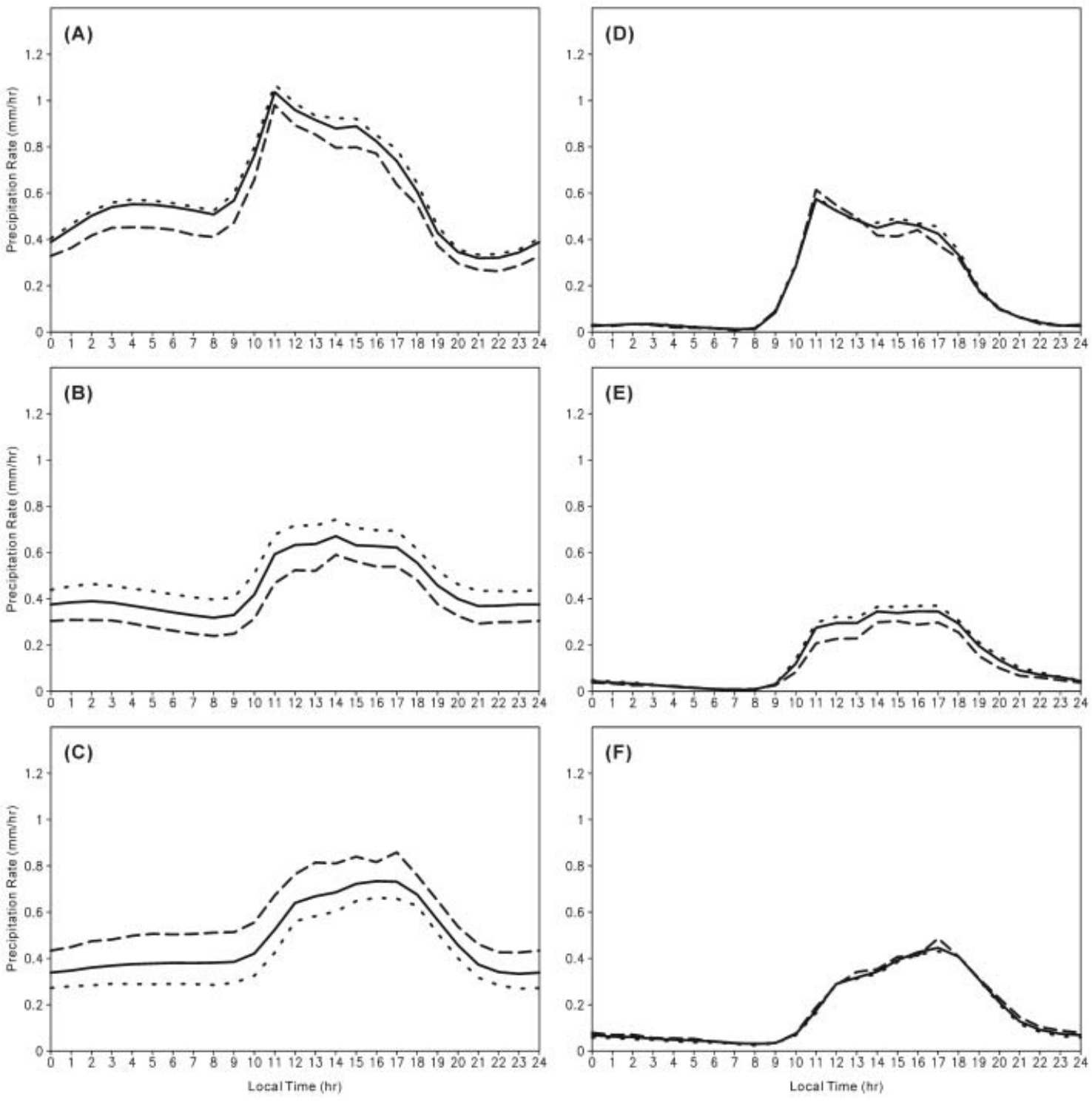

Fig. 9. Composites of the diurnal cycle of rainfall during the westerly, easterly, and mean wind regimes (dotted, dashed, and solid lines, respectively) derived from the simulation. (A), (B), and (C) are total precipitation, while (D), (E), and (F) are the contributions from cumulus precipitation. The sites represented in (A) and (D) are located near Rondonia at $62.5^{\circ} \mathrm{W}, 12^{\circ} \mathrm{S}$; (B) and (E) are located near Brasilia at $47^{\circ} \mathrm{W}, 16^{\circ} \mathrm{S}$; and $(\mathrm{C})$ and $(\mathrm{F})$ are located at the 'Andes' site $\left(75^{\circ} \mathrm{W}, 10^{\circ} \mathrm{S}\right)$ (see Fig. 1).

\section{Links between wind regimes and intraseasonal variability}

In light of the discussion presented in the Introduction section, we now examine possible links between the wind regimes and modes of intraseasonal variability in the South Pacific upstream of South America. Intraseasonal vari- ability in the South Pacific is generally described in terms of the two leading empirical orthogonal functions (EOFs) of geopotential height or stream function anomalies. These EOFs have wavetrain patterns that are known as the Pacific-South American modes (PSA1 and PSA2; Mo 2000; Mo and Nogués-Paegle 2001). PSA1 and PSA2 explain comparable 
amounts of the variance and have similar structures that are approximately in quadrature of phase. It is currently debated as to whether PSA1 and PSA2 represent different phases of a propagating wave or independent modes of variability that happen to explain comparable amounts of the variance (Robertson and Mechoso 2003). Whatever the outcome of the debate, the results of Liebmannn et al. (1999), Robertson and Mechoso (2000), and Diaz and Aceituno (2003) suggest a connection between the South American climate and intraseasonal variability over the South Pacific. In other relevant work, Mo and Nogués-Paegle (2001) showed that PSA2 at intraseasonal time scales is associated with rainfall anomalies over South America that have a dipole pattern with out-of-phase centers on the SACZ and the subtropics around $35^{\circ} \mathrm{S}$. Robertson and Mechoso (pers. com. 2006) speculated that the influence of the largely stationary PSA intraseasonal modes on South America and the SACZ can be understood in terms of downstream development. Our approach herein is based on this line of thought.

Figure 10 shows the composites of 10-70 days band-pass filtered geopotential height anomalies at $700 \mathrm{mb}$ during wind regimes that are longer than 6 days in duration. The figure also shows the composites at different time lags during the evolution of the regimes, in which the origin of the time lags corresponds to the starting date of the regime.

The lag composites of EWRs show a clear PSA2 pattern in the South Pacific with a node around $120^{\circ} \mathrm{W}, 50^{\circ} \mathrm{S}$ just 1 day prior to the start of an easterly regime (LAG $=-1$ ). This wavy structure appears to propagate rapidly toward South America at $\mathrm{LAG}=+3$. The pattern of geopotential anomalies at $\mathrm{LAG}=+5$ is similar to the total composites of EWR, and the corresponding composites of WWRs closely resemble a PSA1 pattern with a maximum around $120^{\circ} \mathrm{W}$ at $\mathrm{LAG}=-1$. Unlike the propagating wave behavior in the EWR, the wavetrain associated with WWRs is quasi-stationary in the South Pacific Ocean from LAG $=-1$ to $\mathrm{LAG}=+5$; however, the negative anomaly downstream of the PSA1 extends over the entire South American Continent during these 6 days. These results indicate that EWR and WWR tend to develop in association with differ- ent phases of intraseasonal variability both upstream and over South America.

\section{Summary and discussion}

We investigated the submonthly variability of SAMS represented by WWRs and EWRs, which were defined as periods of 3 days or longer during which time the direction of low-level wind in central Amazonia was consistently from the west or the east, respectively. We also examined associated changes in the diurnal cycle of rainfall. The analyses were based on observations and numerical model datasets for the austral summer (DJF).

The NCEP/NCAR Reanalysis shows strong interannual variability in the number of WWR days; only a small number of austral summers have a substantial number of EWR days. In both wind regimes, the composite of anomalous precipitation over South America shows a dipole pattern. During WWRs, the SACZ, monsoon high, and subtropical jet stream in the South American sector are relatively strong, as is cyclonic flow over southeastern South America; the approximately opposite behavior is observed during EWRs.

The UCLA AGCM simulation captures the precipitation dipole and circulation patterns, although the amplitudes are weaker than those observed. During WWR (EWR) days, the anomalous moisture flux is greatest over the Amazon Basin. This pattern in consistent with increased moisture flux from the negative to the positive component of the anomalous precipitation dipole.

The CEOP MOLTS show that in central Amazonia (Rondonia), rainfall during EWRs has two peaks during the day, with a stronger peak in the early afternoon and a weaker peak in the early morning. Convective processes provide the dominant contribution to both peaks. The stronger early-morning rainfall during EWR days is also due to stronger convective activity. In the SACZ region (Brasilia), MOLTS produced in different centers show significant variation. A peak is still recorded in the afternoon, and EWR days record little precipitation during the morning. One MOLTS (NCEP) shows a nocturnal peak on WWR days that is even stronger than the afternoon peak, while other MOLTS (UKMO and JMA) show a much weaker nocturnal peak. The diurnal cycles of 


\section{$700 \mathrm{mb}$ Geopotential Height Anomaly}

\section{Easterly Regime \\ Westerly Regime}
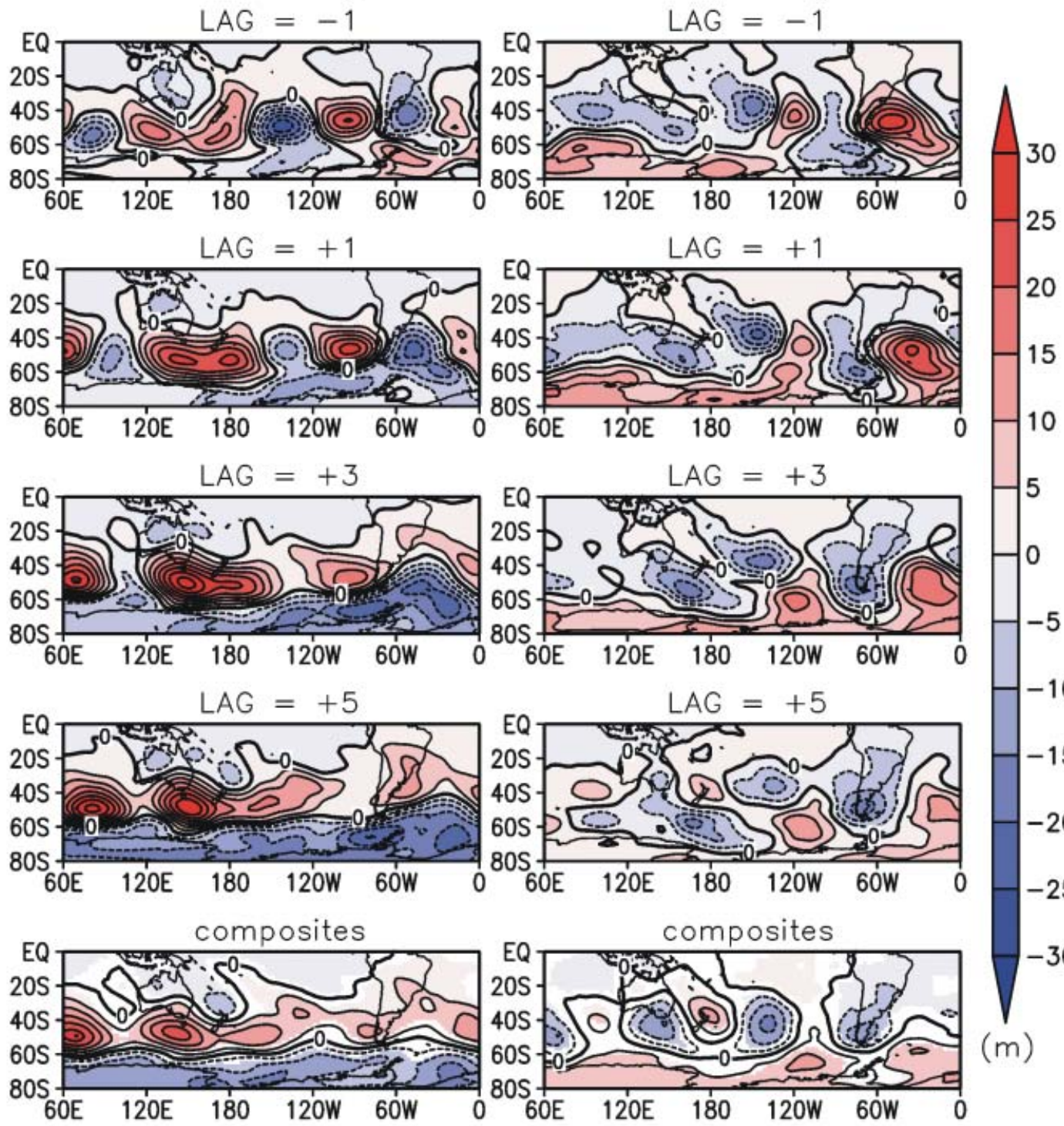

$$
\text { cint }=5(\mathrm{~m})
$$

Fig. 10. Composites of 10-70 days band-pass filtered geopotential height anomalies at $700(\mathrm{mb})$ during wind regimes that are longer than 6 days in duration. The shading corresponds to values that are significant at the $95 \%$ confidence level (bottom two). Lag composites are shown at different times during the evolution of the regimes, in which the origin of the time lags corresponds to the starting date.

rainfall during WWRs and EWRs in the MOLTS simulated by the AGCM are largely identical. Both simulations fail to reproduce the early-morning rainfall maximum, and the total values are almost identical to those associated with convective activity.

The work presented herein confirms the usefulness of the CEOP datasets in terms of facili- 
tating access to the information required for this type of research. Thus far, we have only used part of the information provided by MOLTS for sites in Amazonia. Continuation of the research will require a more comprehensive examination of the MOLTS and the use of insitu data from GEWEX Reference Sites within the SAMS region. Our results raise several questions that are summarized in the following paragraphs.

What are the mechanisms that give rise to the different wind regimes? Previous studies have indicated that the variability represented by the wind regimes is associated with MJO; however, we reproduced the regimes in simulations with an AGCM that, as with many others, underestimate the intraseasonal variability in the tropics (Inness and Slingo 2003). Alternatively, we presented evidence that the wind regimes are associated with the downstream development of the Pacific-South American (PSA) patterns or 'modes'. Accordingly, the development of the two wind regimes over Amazonia during the warm season is at least partly due to internal variability within the extratropical atmosphere.

Which mechanisms contribute to the interannual variability of WWRs and EWRs? SST anomalies influence the onset, evolution, and withdrawal of SAMS. Over tropical South America during El Niño events, rising motion tends to be weaker than average and rainfall over the eastern Amazon and northeast Brazil is below average; during La Niña, the broadly reverse situation is observed (e.g., Marengo and Hastenrath 1993). SACZ variability has also been linked to north-south dipolar SST anomalies over the Southwest Atlantic and SST anomalies over the subtropical South Atlantic of the type identified by Venegas et al. (1996). So far, however, no clear associations have been reported between wind regimes and the interannual variability of SST anomalies.

Why do the AGCM's fail to capture the earlymorning precipitation maximum? Successful simulation of the diurnal cycle in the monsoon regions requires a unified representation of turbulence, dry-convective, and shallow and deep moist-convective processes as a highly interactive system. The difficulties involved in using AGCMs to simulate precipitation are well known (e.g., Yang and Slingo 2001). The failure of the model may reflect any one of a large number of reasons. AGCMs tend to underestimate the activity of shallow convection, and ours is no exception. Shallow convection is one of the processes that is potentially responsible for the early-morning precipitation peak. The lack of early-morning convection may also reflect the over-prediction of PBL stratocumulus simulated by the model at night above cold ground. Halverson et al. (2002) reported that low- and mid-level humidity show substantial variation between the different wind regimes. This finding is important in terms of the formation of stratiform rain, cloud cover, and thermal instability during the regimes. If nocturnal stratocumulus clouds are over-predicted (or equivalently, if stratocumulus destruction in the morning is under-predicted), then the soil and PBL temperatures would remain cold, preventing the development of convection until late in the day. Accordingly, the lack of a morning precipitation peak may result from the difficulties encountered in simulating PBL-free atmosphere interaction in the tropics. Nevertheless, any improvements to traditional AGCMs will not solve the problem if the feature is due to propagating squall lines or mesoscale processes such as those described by Carbone et al. (2002) east of the Rocky Mountains during the boreal summer.

\section{Acknowledgements}

This research was supported by NOAA under Grant NA030AR4310095. The authors wish to thank CEOP for providing the MOLTS datasets used in this study and two anonymous reviewers for their helpful comments.

\section{References}

Arakawa, A., 2000: A personal perspective of the early years of general circulation modeling at UCLA. General Circulation Model Development: Past, Present, and Future. Proceedings of a Symposium in Honor of Professor Akio Arakawa, D.A. Randall, Ed., Academic Press, $1-65$.

Arakawa, A. and W.H. Schubert, 1974: Interaction of a cumulus ensemble with the large-scale environment. Part I. J. Atmos. Sci., 31, 674-701.

Betts, A.K., J. Fuentes, M. Garstang, and J.H. Ball, 2002: Surface diurnal cycle and boundary layer structure over Rondonia during the rainy 
season. J. Geophys. Res., 107(D20), 8065, doi:10.1029/2001JD000356.

Carbone, R.E., J.D. Tuttle, D.A. Ahijevych, and S.B. Trier, 2002: Inferences of predictability associated with warm season precipitation episodes. J. Atmos. Sci., 59, 2033-20056.

Carvalho, L.M.V., C. Jones, and M.A. Silva Dias, 2002: Intraseasonal large-scale circulations and mesoscale convective activity in tropical South America during the TRMM-LBA campaign. J. Geophys. Res., 107(D20), 8042, doi:10.1029/2001JD000745.

Cifelli, R., W.A. Petersen, L.D. Carey, S.A. Rutledge, and M.A.F. Silva Dias, 2002: Radar observations of the kinematic, microphysical, and precipitation characteristics of two MCSs in TRMM LBA. J. Geophys. Res., 107(D20), 8077, doi:10.1029/2000JD000264.

Diaz, A. and P. Aceituno, 2003: Atmospheric circulation anomalies during periods of enhanced and reduced convective cloudiness over Uruguay. $J$. Climate., 16, 3171-3185.

Gan, M.A., V.E. Kousky, and C.F. Ropelewski, 2004: The South America monsoon circulation and its relationship to rainfall over west-central Brazil. J. Climate., 17, 47-66.

Halverson et al., 2002: Environmental characteristics of convective systems during TRMM-LBA. Mon. Wea. Rev., 130, 1493-1509.

Harshvardhan, R. Davies, D.A. Randall, and T.G. Corsetti, 1987: A fast radiation parameterization for atmospheric circulation models. J. Geophys. Res., 92, 1009-1016.

Harshvardhan, R. Davies, D.A. Randall, T.G. Corsetti, and D.A. Dazlich, 1989: Earth radiation budget and cloudiness simulations with a general circulation model. J. Atmos. Sci., 46 , 1922-1942.

Inness, P.M. and J.M. Slingo, 2003: Simulation of the Madden-Julian Oscillation in a coupled general circulation model. Part I: Comparisons with observations and an atmosphere-only GCM. J. Climate, 16, 345-364.

Jones, C. and L.M.V. Carvalho, 2002: Active and break phases in the South American monsoon system. J. Climate, 15, 905-914.

Kalnay, E., M. Kanamitsu, R. Kistler, W. Collins, D. Deaven, L. Gandin, M. Iredell, S. Saha, G. White, J. Woollen, Y. Zhu, A. Leetmaa, B. Reynolds, M. Chelliah, W. Ebisuzaki, W. Higgins, J. Janowiak, K.C. Mo, C. Ropelewski, J. Wang, R. Jenne, and D. Joseph, 1996: The NECP/ NCAR 40-Year Reanalysis Project. Bull. Amer. Meteor. Soc., 77, 437-471.

Li, J.-L.F., A. Arakawa, and C.R. Mechoso, 1999: Revised planetary boundary layer moist processes in the UCLA General Circulation Model.
Tenth Symposium on Global Change Studies, 10-15 January 1999, Dallas, Texas, American Meteorological Society.

Li, J.-L., M. Köhler, J.D. Farrara, and C.R. Mechoso, 2002: The impact of stratocumulus cloud radiative properties on surface heat fluxes simulated with a general circulation model. Mon. Wea. Rev., 130, 1433-1441.

Liebmann, B. and D. Allured, 2005: Daily precipitation grids for South America. Bull. Amer. Meteor. Soc., 86, 1567-1570.

Liebmann, B., G.N. Kiladis, J.A. Marengo, T. Ambrizzi, and J.D. Glick, 1999: Submonthly convective variability over South American and the South Atlantic convergence zone. J. Climate., 12, 1877-1891.

Liebmann, B. and C.A. Smith, 1996: Description of a complete (interpolated) outgoing longwave radiation dataset. Bull. Amer. Meteor. Soc., 77, 1275-1277.

Machado, L.A.T., H. Laurent, and A.A. Lima, 2002: Diurnal march of the convection observed during TRMM-WETAMC/LBA. J. Geophys. Res., 107(D20), 8064, doi:10.1029/2001JD000338.

Madden, R.A. and P.R. Julian, 1972: Description of global-scale circulation cells in the tropics with a 40-50 day period. J. Atmos. Sci., 29, 11091123.

Marengo, J.A., I. Druyan, and S. Hastenrath, 1993: Observational and modeling studies of Amazonia interannual climate variability. Climatic Change, 23, 267-286.

Marengo, J.A., G. Fisch, C. Morales, I. Vendrame, and P. Dias, 2002: Diurnal variability of rainfall in Southwest Amazonia during the LBATRMM field campaign of the Austral summer of 1999. Acta Amazonica, 34, 593-603.

Mechoso, C.R., J.-Y. Yu, and A. Arakawa, 2000: A coupled GCM pilgrimage: From climate catastrophe to ENSO simulations. General Circulation Model Development: Past, present and future. Proceedings of a Symposium in Honor of Professor Akio Arakawa. D.A. Randall, Ed., Academic Press, 539-575.

Mo, K.C., 2000: Relationships between low-frequency variability in the Southern Hemisphere and sea surface temperature anomalies. J. Climate., 13, 3599-3610.

Mo, K.C. and J. Nogués-Paegle, 2001: The PacificSouth American modes and their downstream effects. Int. J. Climatol., 21, 1211-1229.

Nogues-Paegle, J., C.R. Mechoso, R. Fu, E.H. Berbery, W.C. Chao, T.-C. Chen, K. Cook, A.F. Diaz, D. Enfield, R. Ferreira, A.M. Grimm, V. Kousky, B. Liebmann, J. Marengo, K. Mo, J.D. Neelin, J. Paegle, A.W. Robertson, A. Seth, C.S. Vera, and J. Zhou, 2003: Progress in Pan 
American CLIVAR Research: Understanding the South American Monsoon. Meteorologica, 27, 3-33.

Pan, D.-M. and D.A. Randall, 1998: A cumulus parameterization with a prognostic closure. Quart. J. Roy. Meteor. Soc., 124, 949-981.

Reynolds, R.W. and T.M. Smith, 1994: Improved global sea surface temperature analyses using optimum interpolation. J. Climate, 7, 929-948.

Rickenbach, T.M., 2004: Nocturnal cloud systems and the diurnal variation of clouds and rainfall in southwestern Amazonia. Mon. Wea. Rev., 132, 1201-1219.

Rickenbach, T.M., R.N. Ferreira, J.B. Halverson, D.L. Herdies, and M.A.F.S. Dias, 2002: Modulation of convection in the southwestern Amazon basin by extratropical stationary fronts. J. Geophys. Res., 107(D20), 8040, doi:10.1029/ 2000JD000263.

Robertson, A.W. and C.R. Mechoso, 2000: Interannual and interdecadal variability of the South Atlantic Convergence Zone. Mon. Wea. Rev., 128, 2947-2957.

Robertson, A.W. and C.R. Mechoso, 2003: Circulation regimes and low-frequency oscillations in the South Pacific sector. Mon. Wea. Rev., 131, 1566-1576.
Silva Dias, M.A.F., S. Rutledge, P. Kabat, P.L. Silva Dias, C. Nobre, G. Fisch, A.J. Dolman, E. Zipser, M. Garstang, A.O. Manzi, J.D. Fuentes, H.R. Rocha, J. Marengo, A. Plana-Fattori, L.D.A. Sá, R.C.S. Alvalá, M.O. Andreae, P. Artaxo, R. Gielow, and L. Gatti, 2002: Clouds and rain processes in a biosphere atmosphere interaction context in the Amazon region. $J$. Geophys. Res., 107, 8072, doi:10.1029/ 2001JD000335.

Suarez, M.J., A. Arakawa, and D.A. Randall, 1983: The parameterization of the planetary boundary layer in the UCLA general circulation model: formulation and results. Mon. Wea. Rev., 111, 2224-2243.

Venegas, S.A., L.A. Mysak, and D.N. Straub, 1996: Evidence for interannual and interdecadal climate variability in the South Atlantic. Geophys. Res. Lett., 23, 2673-2676.

Vera, C., W. Higgins, J. Amador, T. Ambrizzi, R. Garreaud, D. Gochis, D. Gutzler, D. Lettenmaier, J. Marengo, C.R. Mechoso, J. NoguesPaegle, P.L. Silva Dias, and C. Zhang: A Unified View of the American Monsoon Systems. J. Climate. In press.

Yang, G.-Y. and J. Slingo, 2001: The diurnal cycle in the tropics. Mon. Wea. Rev., 129, 784-801. 